\title{
sciendo
}

CIVIL AND ENVIRONMENTAL ENGINEERING REPORTS

E-ISSN 2450-8594

CEER 2020; 30 (4): 0056-0071

DOI: $10.2478 /$ ceer-2020-0050

Original Research Article

\section{FORMULATION OF A CONCRETE BASED ON GRINDED SEASHELLS AS PARTIAL SUBSTITUTION FOR SAND}

\author{
Khaled BOUDJELLAL ${ }^{1}$, Mohamed BOUABAZ ${ }^{1}$, Salah Eddine BENSEBTI ${ }^{2}$ \\ ${ }^{1}$ Department of Civil Engineering, LMGHU Laboratory, Université 20 août 1955- \\ Skikda, Algeria \\ ${ }^{2}$ Department of Civil Engineering, Materials, and Construction Durability Laboratory, \\ University Mentouri, Constantine, Algeria
}

\begin{abstract}
This paper examines the partial substitution of concrete components by grinded sea mussel shells collected from the coastal region of eastern Algeria. The study proposes the recycling of this waste to reduce the excessive and increasing accumulation of these shells to relieve the marine environment. The problem lies in establishing a perfect integration of the aggregates obtained from the grinded shells of sea mussels in the formulation of various types of concrete. These substitutions significantly affect the rheology of fresh cementitious materials, which is directly related to the development of strength, modulus of elasticity, and the durability of the hardened material. The objective is to partially replace the mineral sand used in the manufacture of ordinary concrete with shell sand from grinded sea mussels, with different substitution percentages of $20 \%, 25 \%, 35 \%, 40 \%$, and $50 \%$ of sand volume. The results obtained indicate a marked improvement in the characteristics of fresh concrete with minimum loss in mechanical performance.
\end{abstract}

Keywords: mineral aggregates, concrete, cement, sand, formulation, substitution, characterization

\footnotetext{
${ }^{1}$ Corresponding author: khaled BOUDJELLAL, Department of Civil Engineering, LMGHU Laboratory, Université 20 août 1955-Skikda, Algeria, k.boudjellal@univ-skikda.dz
} 


\section{INTRODUCTION}

Concrete was born out of the need to have an economical building material, malleable at the time of its implementation, and sufficiently resistant when used in the structure. The optimization of these three parameters to respond to important developments both in terms of architecture and structure has led to excessive consumption of aggregates of mineral origin. This exploitation has continuously increased to the point where, in recent years, environmental imbalances have arisen in multiple regions around the world. In parallel, the development of the industry and the introduction of food technology have become a source of various by-products and wastes whose storage or disposal pose enormous ecological and economic challenges.

The concern of manufacturers is to achieve the formulation of ecological concrete with a judicious choice of aggregates and the addition of new products such as local natural materials or waste from different industries.

Algeria, with its coastline of $1,200 \mathrm{~km}$, has a large reserve of seashells whose mineralogical composition, rich in limestone, can be an alternative to mineral aggregates. Similarly, the waste from the agri-food industries active in the processing of oyster products (mussel farming) is starting to constitute a constraint as regards their storage and disposal. Fortunately, due to the strong presence of industrial and maritime waste in the Skikda region, we were able to conduct research at the Research Unit of Building Materials (RUBM) at the LMGHU Laboratory, University of Skikda, to study the feasibility of the reuse of waste in the field of civil engineering, which normally comes from quarries $[3,6]$. It is, therefore, in the interest of the laboratory team to consider the exploitation of marine waste in the manufacture of concrete as a partial or total alternative to the standard constituents of concrete, as an innovative material.

Several researchers are interested in studying the technical feasibility of the exploitation of mussel shells in the field of civil engineering, as either a partial or total alternative constituent of concrete and mortar [5, 9, and 13]. A study conducted by Barbachi [1] on the physical characterization of sea shells for a concrete formulation concluded that the shells of crushed mussels can be candidates as constituents of lightweight concrete. They argued that the results obtained by calculating the percentage of vacuum showed that the crushed shells have low compactness compared to the sands studied. Later, Barbachi [2] extended the research to the study of the physico-chemical analysis of mussel shells using an X-ray diffraction (XRD) method. They noted that the shell of the mussel is mainly composed of calcium carbonate $\mathrm{CaCo}_{3}$ at $94.42 \%$, and the other components are organic matter and other minerals in trivial amounts, which results were previously confirmed by Martinez-Garcia [10], who reported about $95 \%$ calcium carbonate. 
Studies on the use of crushed queen shells were conducted by numerous researchers $[4,8]$ who concluded that the use of this material as an aggregate replacement could decrease the mechanical properties and increase the porosity as a result of increased trapped air in the concrete. They argued that uncrushed cockleshells could replace aggregate partially, up to $20 \%$, with an increase in compressive strength compared to normal concrete. Muthusamy [12] confirmed low workability due to the characteristics of the material such as the size, shape, and texture of the shells. A review of the recycling of seashell waste in concrete was conducted $[7,11]$ which suggested that seashell waste could be utilized as a partial aggregate at a replacement level of up to $20 \%$ for adequate workability and strength of concrete for non-structural purposes.

The objective of this experimental study consists of considering the partial substitution of the mineral sand used in the manufacture of ordinary concrete by a sand of grinded marine shells, collected on the coasts of the region of Skikda Algeria, and to obtain an optimal formulation for making a new sand concrete using different percentages of substitution; $20 \%, 25 \%, 35 \%, 40 \%$, and $50 \%$ of sand volume, with a well-determined percentage of grinded marine shells, thereby reducing the exploitation of mineral aggregates, decreasing the pollution caused by the quarrying of aggregates.

\section{EXPERIMENTAL STUDY AND METHODOLOGY}

\subsection{Characteristics of the materials used}

It is clear that the properties of hardened and fresh concretes depend to a large extent on the characteristics of the materials used in their composition. Therefore, we will focus on the characteristics of the materials used, namely cement, sand, water, gravel, and grinded shells, the origins and availability of which will be specified. However, it should be noted that the concretes studied are designed without the addition of admixtures or mineral additions.

\subsection{Characteristics of the cement}

The cement used is a Portland Cement Compound, type CEM / II.A-M (S.L) 42. The gravel used comes from Mazla Ain Abid, Constantine quarry, which is known as a rich region by virtue of its numerous giant quarries. The characterizations of the different materials are illustrated in the following Tables (1), (2), and (3). 
FORMULATION OF A CONCRETE BASED ON GRINDED SEASHELLS AS PARTIAL 59 SUBSTITUTION FOR SAND

Table 1. Characteristics of the cement

\begin{tabular}{|c|l|c|c|}
\hline Item & \multicolumn{1}{|c|}{ Characteristics } & Value & Unit \\
\hline 1 & Clinker content & $80-94$ & $\%$ \\
\hline 2 & $\begin{array}{l}\text { High Furnace slump (S) and limestone (L) } \\
\text { content }\end{array}$ & $6-20$ & $\%$ \\
\hline 3 & Fire loss & $\leq 5.0$ & $\%$ \\
\hline 4 & Insoluble residue & $\leq 5.2$ & $\%$ \\
\hline 5 & Sulfate content & $\leq 3.5$ & $\%$ \\
\hline 6 & Chloride content & $\leq 0.1$ & $\%$ \\
\hline 7 & Taking start time & 50 & $\mathrm{~min}$ \\
\hline 8 & Short-term compressive strength & $\leq 10$ & $\mathrm{MPa}$ \\
\hline 9 & Stability (expansion) & $\mathrm{mm}$ \\
\hline
\end{tabular}

Table 2. Characteristics of the sand

\begin{tabular}{|c|l|c|c|}
\hline Item & \multicolumn{1}{|c|}{ Characteristics } & Measured value & Unit \\
\hline 1 & Granular class & $0 / 4$ & $\mathrm{~mm}$ \\
\hline 2 & Fineness modular & 2.78 & \\
\hline 3 & Sand equivalent & 81 & $\%$ \\
\hline 4 & Apparent density & 1.73 & $\mathrm{~kg} / \mathrm{l}$ \\
\hline 5 & Absolute density & 2.66 & $\mathrm{gr} / \mathrm{cm}^{3}$ \\
\hline 6 & Water content $(\mathrm{w})$ & 12.02 & $\%$ \\
\hline
\end{tabular}

Table 3. Characteristics of the gravel

\begin{tabular}{|c|l|c|c|}
\hline Item & \multicolumn{1}{|c|}{ Characteristics } & Measured value & Unit \\
\hline 1 & Porosity (P) & 1.35 & $\%$ \\
\hline 2 & Apparent volumic mass & 1.54 & $\mathrm{~kg} / 1$ \\
\hline 3 & Absolute volumic density & 2.63 & $\mathrm{gr} / \mathrm{cm}^{3}$ \\
\hline 4 & Granular class & $8 / 15$ & $\mathrm{~mm}$ \\
\hline
\end{tabular}

\section{SHELL AGGREGATES}

\subsection{Preparation of grinded shells}

After washing the collected shells by total immersion in water for 35 minutes and cleaning with a brush to remove impurities, including organic, they were wiped one by one and weighed. A weight of $17544 \mathrm{~g}$ was obtained. 
The shells were introduced into the oven for one hour at $105^{\circ} \mathrm{C} \pm 5$ and then reweighed. The weight obtained was $17532 \mathrm{~g}$. The operation was repeated until a constant weight of $17525 \mathrm{~g}$ was obtained. Then, the crushing of the shells was carried out using a jaw grinder as shown in Figure 1.

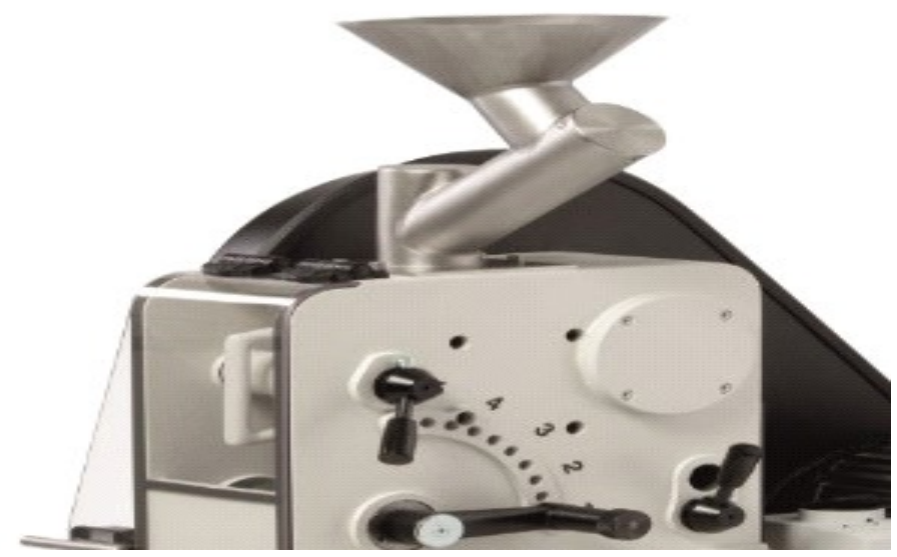

Fig. 1. Jaw grinder

\subsection{Chemical analysis of shells}

Chemical analysis was carried out on the ground shells powder at the GICA Group Laboratory in Skikda. According to the chemical analysis, the mineralogical nature of the marine shells is $96.98 \%$ limestone. The result of the analysis is illustrated in Table 4.

Table 4. Chemical analysis of shells

\begin{tabular}{|c|c|c|c|}
\hline Designation & $\begin{array}{c}\text { Result } \\
\%\end{array}$ & Designation & $\begin{array}{c}\text { Result } \\
\%\end{array}$ \\
\hline $\mathrm{CaO}$ & 54.31 & $\mathrm{Na}_{2} \mathrm{O}$ & 00 \\
\hline $\mathrm{Al}_{2} \mathrm{O}_{3}$ & 0.1 & $\mathrm{~K}_{2} \mathrm{O}$ & 00 \\
\hline $\mathrm{Fe}_{2} \mathrm{O}_{3}$ & 0.14 & $\mathrm{Cl}^{-}$ & 00 \\
\hline $\mathrm{SiO} 2$ & 0.3 & $\mathrm{SO}_{3}$ & 00 \\
\hline $\mathrm{MgO}$ & 1.15 & $\mathrm{PAF}$ & 44 \\
\hline & & Total & 100 \\
\hline & & Titration & 96.98 \\
\hline
\end{tabular}

\subsection{Calculation of the density of the shells}

For the density measurement, the shells were washed one by one to remove all traces of impurity, particularly organic. They were then put in an oven at $105^{\circ} \mathrm{C}$ \pm 5 to remove moisture and obtain dry shells. The shells were weighed and returned to the oven for one hour at $105^{\circ} \mathrm{C} \pm 5$, with an obtained weight of 17532 
g. The same procedure was repeated until a constant weight of $17525 \mathrm{~g}$ was obtained. The weight of the shells remained constant during the 3rd and 4th oven setting, the density of the shells was $2.71 \mathrm{~g} / \mathrm{cm}^{3}$, mainly due to their composition of pure limestone $\left(\mathrm{C}_{\mathrm{a}} \mathrm{CO}_{3}\right)$. The shells are either not very porous or almost closed. The porosity is calculated according to the Formulae (3.1), (3.2), and (3.3) as presented below, and the result of the porosity is presented in Table 5 .

$$
\begin{gathered}
P(\%)=\frac{M 1-M 0}{V} \\
V=\frac{M 0}{M v} \\
p(\%)=\frac{M 1-M 0}{M 0} * M v * 100
\end{gathered}
$$

Were $\mathrm{P}$ is the porosity, $\mathrm{V}$ is the volume, and $\mathrm{M}$ is the mass

Table 5. Porosity of the shells

\begin{tabular}{|c|c|c|c|c|}
\hline Designation & Trial 1 & Trial 2 & Trial 3 & \multirow{2}{*}{ Average } \\
\cline { 1 - 3 } $\mathrm{M}_{0}(\mathrm{~g})$ & 17516 & 17516 & 17516 & \multirow{2}{*}{$0.28 \%$} \\
\cline { 1 - 3 } $\mathrm{M}_{1}(\mathrm{~g})$ & 17544 & 17532 & 17525 & \\
\hline $\mathrm{P}(\%)$ & $0.43 \%$ & $0.27 \%$ & $0.14 \%$ & \\
\hline
\end{tabular}

\subsection{Granulometric analysis of the grinded shells}

The result of the granulometric analysis of the grinded shells is summarized in Table 6.

Table 6. Granulometric analysis of the grinded shells

\begin{tabular}{|c|c|c|c|}
\hline Sieve & $\begin{array}{c}\text { Refusal } \\
(\mathrm{g})\end{array}$ & $\begin{array}{c}\text { Cumulative Passing } \\
(\mathrm{g})\end{array}$ & $\begin{array}{c}\text { Cumulative Passing } \\
(\%)\end{array}$ \\
\hline Bottom & 65,36 & 0,00 & 1,38 \\
\hline $63 \mu \mathrm{m}$ & 101,83 & 167,19 & 3,53 \\
\hline $125 \mu \mathrm{m}$ & 203,20 & 370,39 & 7,82 \\
\hline $250 \mu \mathrm{m}$ & 266,66 & 637,06 & 13,45 \\
\hline $500 \mu \mathrm{m}$ & 523,86 & 1160,91 & 24,51 \\
\hline $1 \mathrm{~mm}$ & 410,65 & 1571,57 & 33,18 \\
\hline $1.25 \mathrm{~mm}$ & 687,27 & 2258,83 & 47,69 \\
\hline $2 \mathrm{~mm}$ & 519,59 & 2778,43 & 58,66 \\
\hline $2.5 \mathrm{~mm}$ & 686,31 & 3464,74 & 73,15 \\
\hline $5 \mathrm{~mm}>\mathrm{D}>3,15$ & 0 & 4736,50 & 100 \\
\hline
\end{tabular}


The granulometric curves of the used aggregates are presented in a logarithmic scale in Figure 2.

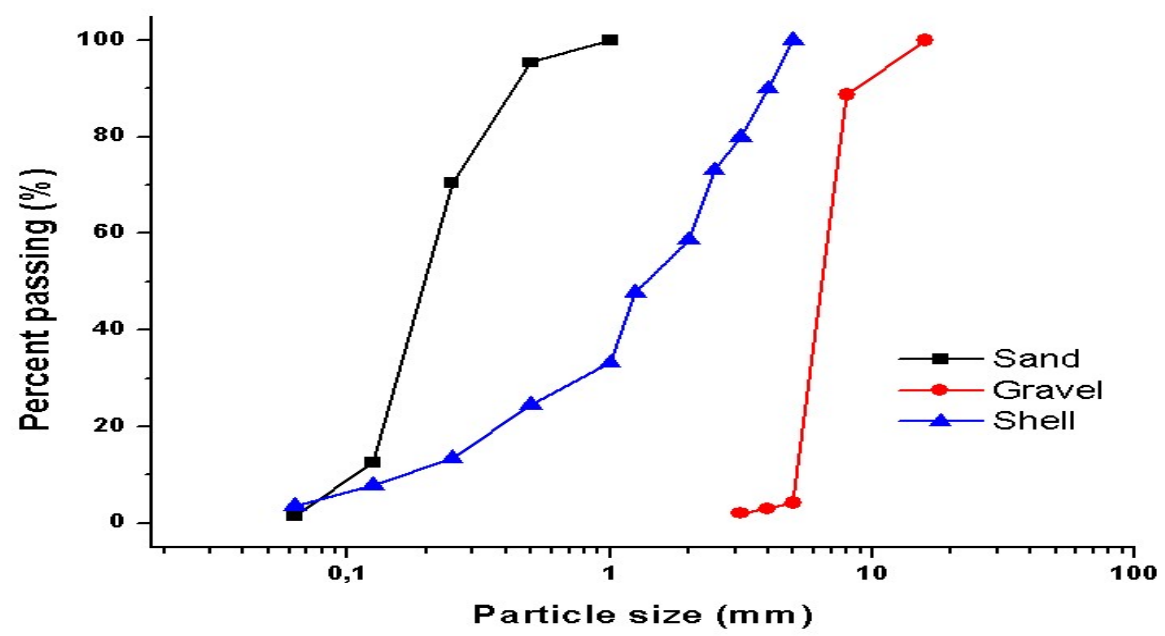

Fig. 2. Size grading curves of used materials

\subsection{Apparent and absolute densities}

The apparent and absolute densities of grinded shells are given in Table 7.

Table 7. Apparent and absolute densities

\begin{tabular}{|l|c|}
\hline \multicolumn{1}{|c|}{ Designation } & Value \\
\hline Apparent density & $1241.0 \mathrm{~kg} / \mathrm{m}^{3}$ \\
\hline Absolute density & $2597.2 \mathrm{~kg} / \mathrm{m}^{3}$ \\
\hline
\end{tabular}

\subsection{Fineness modulus}

The fineness modulus (FM) is determined by the following Formulae (3.4), (3.5), and (3.6) as described below.

$F m=\frac{1}{100} \sum$ cumulative $\%$ refusal sieve $\{0.125-0.25-0.5-1-2-4\}$

Were,

$F m=\frac{1}{100}(7.82+13.45+24.51+33.18+58.6+100)$

Thus, $\mathrm{Fm}=2.38$ 


\subsection{Blaine specific surface (BSS)}

The Blaine specific surface (BSS) of the grinded shells is calculated from a test carried out by the Industrial Group of Cements GICA, subsidiary of HDJAR ESSOUD-Skikda, Algeria, on a shell powder, were the BSS $=6550 \mathrm{~g} / \mathrm{cm}^{2}$.

\section{CONCRETE FORMULATION}

In the absence of a specific method suitable for the formulation of shell concretes, the G. DREUX method was used. This choice is justified by the chemical and mineralogical nature of marine shells similar to the mineral aggregates used in ordinary concrete. Based on an $\mathrm{E} / \mathrm{C}$ ratio $=0.5$ and a $\mathrm{G} / \mathrm{S}$ ratio $=1.9$, the proportions of the various aggregates for a cubic meter of concrete are summarized in Table 8.

Table 8. Mix-composition of specimens

\begin{tabular}{|c|c|c|c|c|c|c|c|}
\hline \multicolumn{2}{|c|}{ Substitution \% } & 00 & 20 & 25 & 35 & 40 & 50 \\
\hline \multirow{7}{*}{ Item } & $\begin{array}{c}\text { Cement } \\
\text { (Kg }\end{array}$ & 350 & 350 & 350 & 350 & 350 & 350 \\
\cline { 2 - 7 } & $\begin{array}{c}\text { Water } \\
(\mathrm{L})\end{array}$ & 175 & 175 & 175 & 175 & 175 & 175 \\
\cline { 2 - 7 } & $\begin{array}{c}\text { Sand } \\
(\mathrm{Kg})\end{array}$ & 630 & 504 & 472.5 & 409.5 & 378 & 315 \\
\cline { 2 - 7 } $\begin{array}{c}\text { Grinded } \\
\text { shells } \\
(\mathrm{Kg})\end{array}$ & 00 & 126 & 157.5 & 220.5 & 252 & 315 \\
\hline $\begin{array}{c}\text { Gravel } \\
(\mathrm{Kg})\end{array}$ & 1200 & 1200 & 1200 & 1200 & 1200 & 1200 \\
\hline
\end{tabular}

\section{PREPARATION OF TEST SAMPLES AND CONSERVATION}

The witness concrete was prepared with a slump to the cone of Abrams class S2 ( 5 to $9 \mathrm{~cm}$ ) with medium workability and medium humidity. The workability increases with the increase in the percentage of substitution, but the concrete has not lost its appearance, such as plastic concrete as detailed in Figures (3), (4), and (5). 

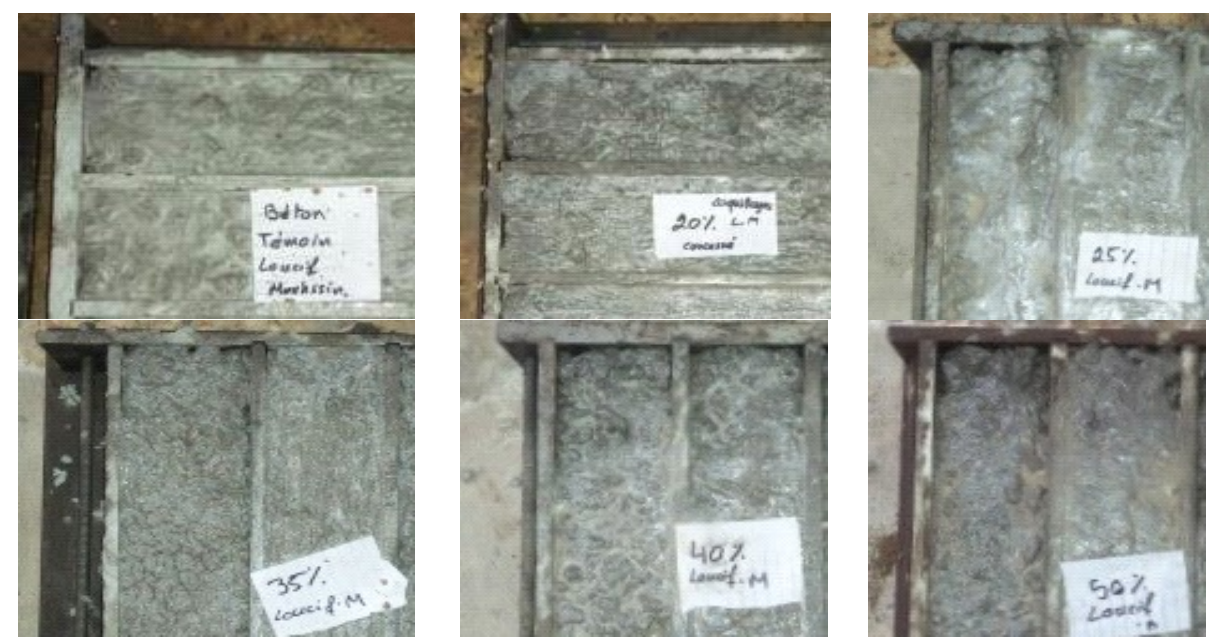

Fig. 3. Concrete poured into test tube molds

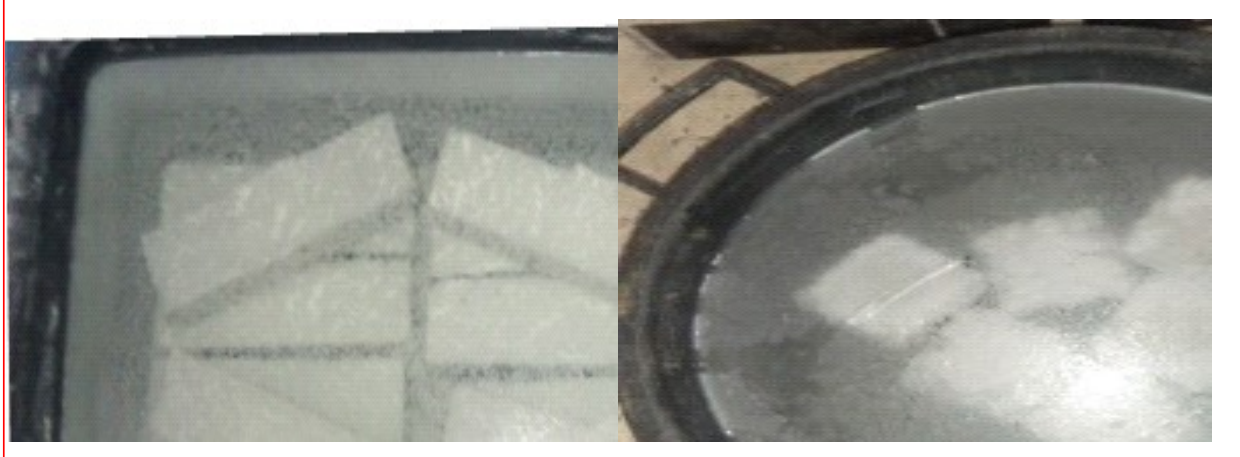

Fig. 4. Storage of test samples after formwork removal

After 27 days of conservation of our test samples, we noticed the presence of concrete segregation in some of them, so we proceeded to the surfacing of these specimens.

The test samples were stripped 24 hours after pouring and kept for 28 days in a storage tank immersed in water at a constant temperature of $22^{\circ} \mathrm{C}$. 


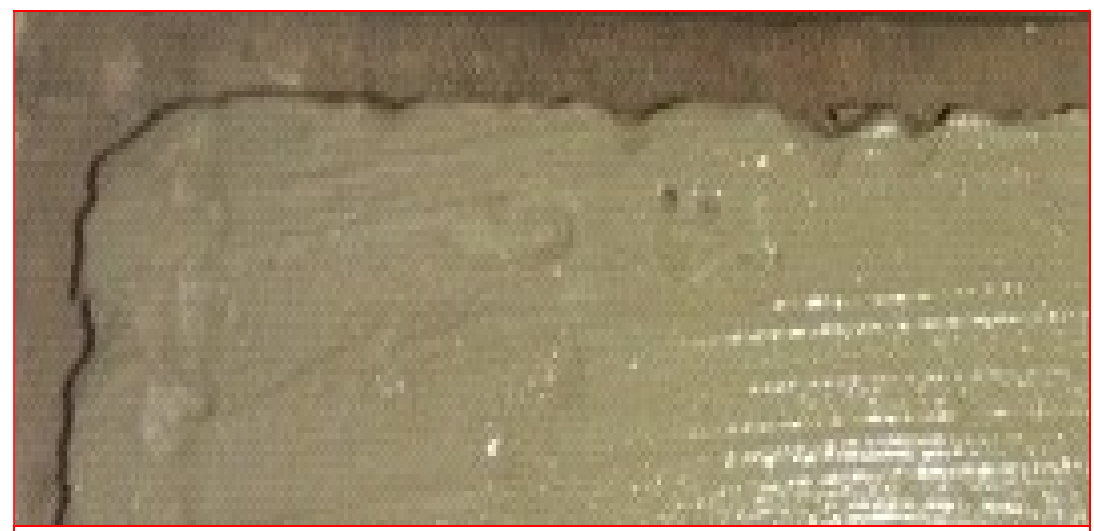

Fig.5. Specimen surfacing

\section{CRUSH RESULTS}

\subsection{The 3 points bending test}

When the concrete had aged for 27 days, the test samples were taken out of the water and left in the ambient air for 24 hours for drying. The next day, that is to say at 28 days, the test samples were crushed one by one under the effect of tensile strength by bending. It can be seen that there is no clearly defined relationship between compressive strength and flexural strength. Generally, it can be assumed for most applications that the flexural strength of normal concrete is about $10 \%$ of the compressive strength obtained for the same concrete.

The rupture line of the test sample is restored in a straight line with the increase in the content of the incorporated crushed shells, as shown in the following Figures (6) and (7). 

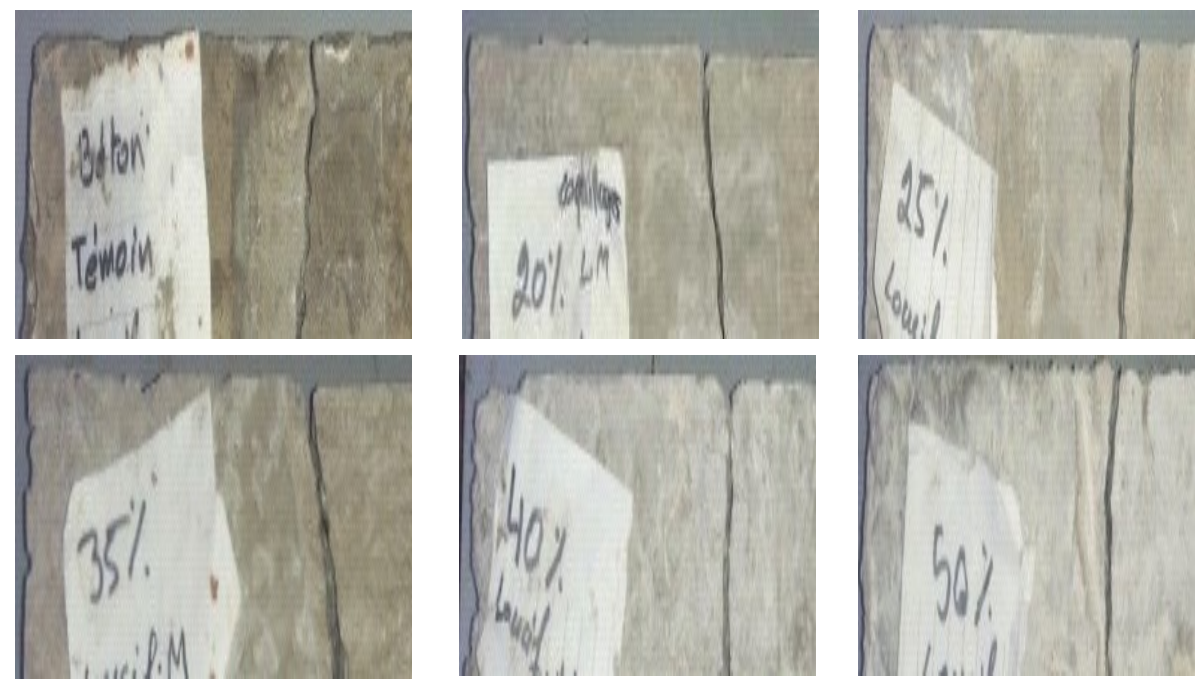

Fig.6. The rupture line of the test sample
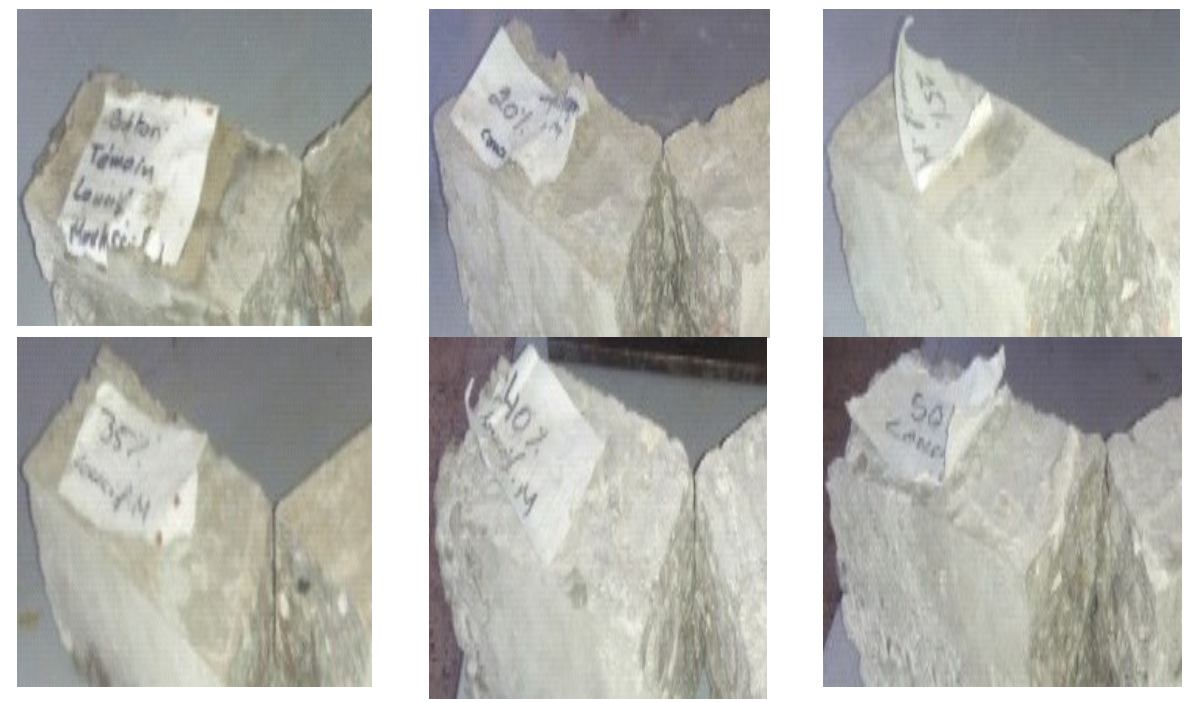

Fig.7. The cross-section line of the test sample

\subsection{The compressive strength}

The compressive strength was used to evaluate criteria for the test mixes.

Results of the compressive and tensile strength are detailed in Table 9. 
FORMULATION OF A CONCRETE BASED ON GRINDED SEASHELLS AS PARTIAL 67 SUBSTITUTION FOR SAND

Table 9. Detailed results of the compressive and tensile strength and the mean strength

\begin{tabular}{|c|c|c|c|c|c|c|c|}
\hline Pubstitution & $\begin{array}{c}\text { Load } \\
\max \\
\text { KN }\end{array}$ & $\begin{array}{c}\text { Compression } \\
\sigma_{\mathrm{c} 28} \\
\mathrm{MPa}\end{array}$ & $\begin{array}{c}\text { Compression } \\
\text { mean } \\
\sigma_{\mathrm{c} 28} \\
\mathrm{MPa}\end{array}$ & $\begin{array}{c}\text { Rate } \\
\text { of } \\
\text { increase } \\
(\%)\end{array}$ & $\begin{array}{c}\text { Tensile } \\
\sigma_{\mathrm{t} 28} \\
\mathrm{MPa}\end{array}$ & $\begin{array}{c}\text { Tensile } \\
\text { Mean } \\
\sigma_{\mathrm{t} 28} \\
\mathrm{MPa}\end{array}$ & $\begin{array}{c}\text { Rate } \\
\text { of } \\
\text { increa } \\
\text { se } \\
(\%)\end{array}$ \\
\hline \multirow{3}{*}{$\begin{array}{l}\text { Witness } \\
\text { concrete }\end{array}$} & 7.25 & 42.83 & \multirow{3}{*}{39.94} & & 3.17 & \multirow{3}{*}{2.997} & \\
\hline & 6.89 & 40.83 & & & 3.05 & & \\
\hline & 6.33 & 36.16 & & & 2.77 & & \\
\hline \multirow{4}{*}{20} & 7.40 & 44 & \multirow{4}{*}{40.33} & \multirow{4}{*}{0.98} & 3.24 & \multirow{4}{*}{3.02} & \multirow{4}{*}{0.77} \\
\hline & 6.54 & & & & & & \\
\hline & 6.77 & 3766 & & & 2.86 & & \\
\hline & 7.77 & 39.33 & & & 2.96 & & \\
\hline \multirow{3}{*}{25} & & 46.66 & \multirow{3}{*}{48.16} & \multirow{3}{*}{20.58} & 3.40 & \multirow{3}{*}{3.49} & \multirow{3}{*}{16.45} \\
\hline & 8.73 & 53.66 & & & 3.82 & & \\
\hline & 7.44 & 44.16 & & & 3.25 & & \\
\hline \multirow{3}{*}{35} & 8.75 & 53.83 & \multirow{3}{*}{48.49} & \multirow{3}{*}{21.41} & 3.83 & \multirow{3}{*}{3.51} & \multirow{3}{*}{17.12} \\
\hline & 8.81 & 54.16 & & & 3.85 & & \\
\hline & 6.53 & 37.5 & & & 2.85 & & \\
\hline \multirow{3}{*}{40} & 8.57 & 52.5 & \multirow{3}{*}{51.94} & \multirow{3}{*}{30.05} & 3.75 & \multirow{3}{*}{3.72} & \multirow{3}{*}{24.12} \\
\hline & 8.63 & 52.83 & & & 3.77 & & \\
\hline & 8.29 & 50.5 & & & 3.63 & & \\
\hline \multirow{3}{*}{50} & 7.75 & 46.5 & \multirow{3}{*}{47.83} & \multirow{3}{*}{19.75} & 3.39 & \multirow{3}{*}{3.47} & \multirow{3}{*}{15.78} \\
\hline & 8.87 & 54.66 & & & 3.88 & & \\
\hline & 7.17 & 42.33 & & & 3.14 & & \\
\hline
\end{tabular}

\section{DISCUSSION OF RESULTS}

Analysis of the results obtained, as illustrated by the curves in Figures 8 and 9 , revealed that the partial substitution of the sand used in the manufacture of concrete by sand resulting from the grinding of marine shells gives very interesting mechanical characteristics. Indeed, it was recorded that progressive substitution of $20,25,35$, and $40 \%$ improves the tensile and compressive strengths of the concrete at 28 days, reaching an optimum at $40 \%$ substitution, with an increased rate for tensile and compressive strength of $24.12 \%$ and $30.05 \%$, respectively. This significant increase seems to be related to the mineralogical nature of the marine shells, which is rich in limestone, and to the fine and continuous granulometry of the sand obtained by the grinding of these shells. The fines contained in the sand of the seashells, with their low rate of water absorption, contributed strongly on the one hand to the maintenance of good workability of the concrete in the fresh state and, on the other hand, to the improvement of its 
compactness at the hardened state, hence the gain recorded in its mechanical performance.

Therefore, the chemical analysis carried out on the seashells corroborates that the inert character of the shells was a harmless action on the hydration reaction of the cement used.

The variations of the tensile strength and the compressive strength at 28 days versus the substitution rate are illustrated graphically below - see Figures (8) and (9).

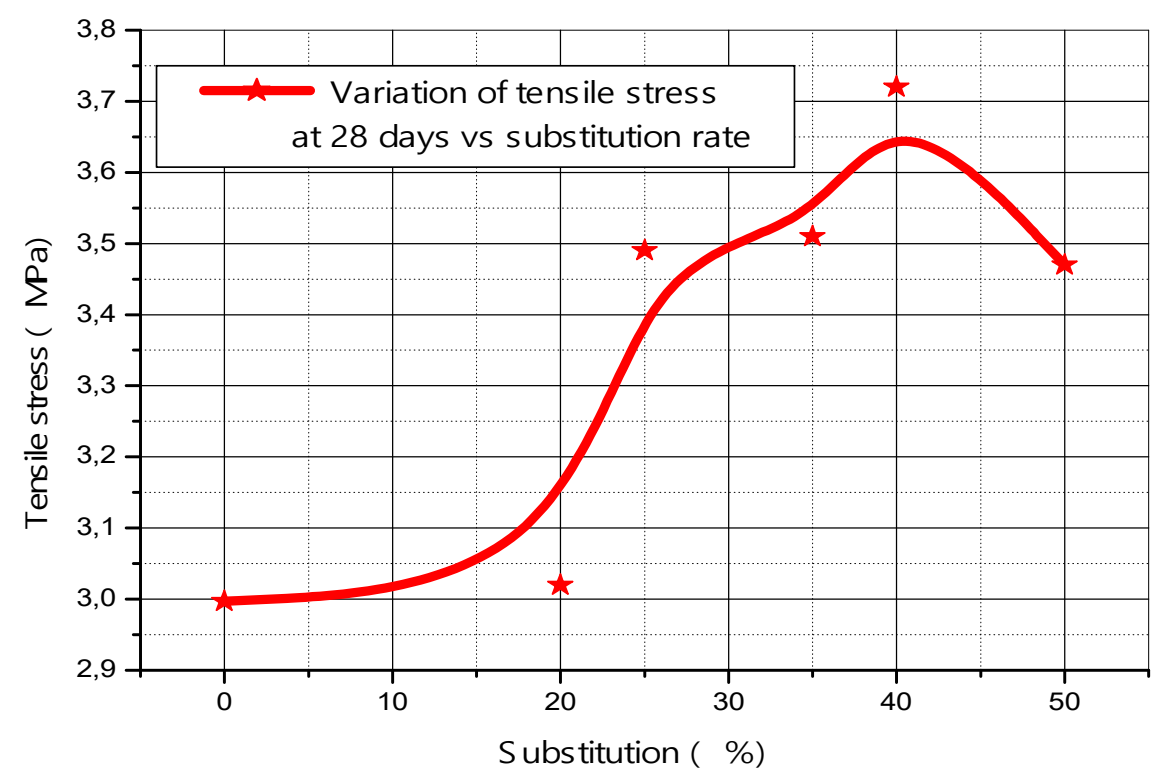

Fig.8.Variation of tensile strength at 28 days versus substitution rate 


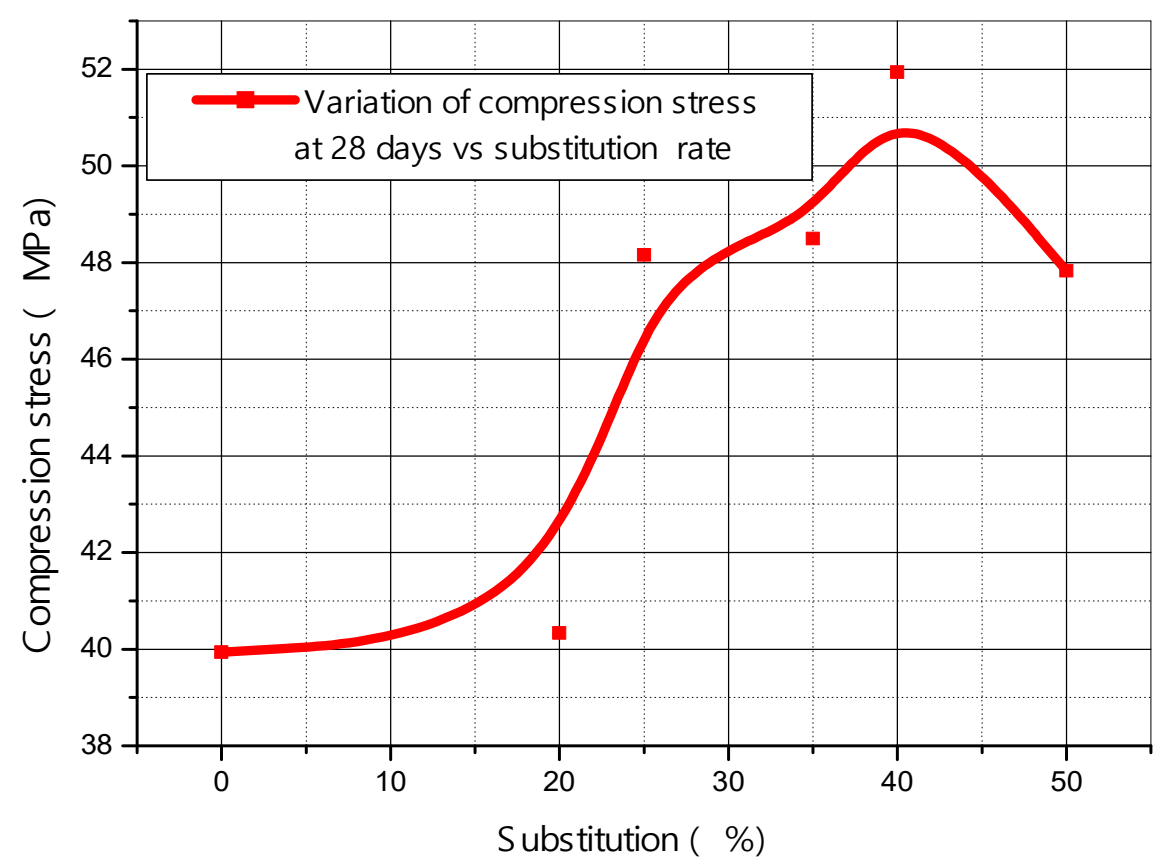

Fig.9. Variation of compression strength at 28 days versus substitution rate

\section{CONCLUSION}

The experimental study carried out on sea mussel shells indicates that the partial substitution of the components of mineral origin of the concrete by aggregates based on the grinded shells of sea mussels is feasible in view of the very encouraging results obtained, and leads to the following conclusions:

- Grinding the shells is very energy efficient.

- A chemical composition rich in calcium is produced, without any interactivity with the other components of concrete.

- A gain in the workability of the concrete is produced.

- A gain in the density of the concrete is produced.

- A good honeycomb structure, giving the composite better thermal and sound insulation properties, is produced.

- This cellular structure makes the concrete permeable and favors its use for soils that need to be drained.

- Low gains in mechanical performance regarding traction and compression of the concrete up to a threshold of $40 \%$ substitution are produced. 
- A light concrete with very appreciable mechanical qualities, partially meeting the requirements of an eco-material, is produced.

For future work, the laboratory plans to use wastes and by-products from the region's petrochemical industry.

\section{REFERENCES}

1. Barbachi, M, El Biriane, M, Bouabaz, M and Boudjellal, K 2019. Physicochemical analysis of mussel shells for use in civil engineering. Applied Journal of Environmental Engineering Science, 5(2), 153-161.

2. Barbachi, M, Abdelatif, I, Jeffali, F, Boudjellal, K and Bouabaz, M 2017. Physical characterization of seashell for a concrete formulation. Journal of Materials and Environment Sciences, 8(1), 332-337.

3. Benhalilou, MI, Belachia, M, Houari, H and Abdelouahed, A 2020. The study of the characteristics of sand concrete based on marble waste sand. Civil and Environmental Engineering Reports, 30 (1) 130-144.

4. Cuadrado Rica, H, Sebaibi, N, Boutouil, M and Boudart, B 2015. Properties of ordinary concretes incorporating crushed queen scallop shells. Materials and Structures, 49, 1805-1816.

5. Ez-zaki, H, Diouri, A, Kamali-Bernard, S and Sassi, O 2016. Composite cement mortars based on marine sediments and oyster shell powder. Materiales de Construccion, 66, 321.

6. Hebhoub, H, Belachia, M and Djebien, R 2014. Introduction of sand marble wastes in the composition of mortar. Structural Engineering and Mechanics, 49(4), 491-498.

7. Kim, HM, Alengaram, UJ, Jumaat, MZ, Lee, SC, Wan, IG and Choon, WY 2018. Recycling of seashell waste in concrete: A review. Construction and Building Material, 162(20), 751-764.

8. Kuo, WT, Wang, HY, Shu, CY and Su, DS 2013. Engineering properties of controlled low-strength materials containing waste oyster shells. Journal of Construction and Building Materials, 46, 128-133.

9. Lusty, PAJ and Gunn, AG 2014. Challenges to global mineral resource security and options for future supply. Geol. Soc. London. Spec. Pub, 393 (23), 265-276.

10. Martinez-Garcia, C, Gonzalez-Fonteboa, BF, Martinez-Abella, F and CarroLopez, D 2017. Performance of mussel shell as aggregate in plain concrete. Construction and Building Materials, 139, 570-583.

11. McNeil, K and Kang, THK 2013. Recycled concrete aggregates: a review. International Journal of Concrete Structures and Materials, 7, 61-69. 
FORMULATION OF A CONCRETE BASED ON GRINDED SEASHELLS AS PARTIAL 71 SUBSTITUTION FOR SAND

12. Muthusamy, K and Sabri, NA 2012. Cockle shell: a potential partial coarse aggregate replacement in concrete. International Journal of Science, Environment and Technology, 1(4), 260-267.

13. Olivia, M and Oktaviani, IR 2017. Properties of concrete containing ground waste cockle and clam seashells. Procedia Engineering, 171, 658-663.

Editor received the manuscript: 18.09.2020 